GODDARD : ORGANO-DERIVATIVES OF THALLIUM. PART III.

\title{
VII.-Organo-derivatives of Thallium. Part III. Some Thalliumdialkyl Salts and the Preparation of Thalliumdiaryl Haloids.
}

\section{By Archibald Edwin Goddard.}

IN a previous communication (Goddard, 'T., 1921, 119, 672) it was shown that thalliumdialkyl haloids reacted readily with silver salts. This has now been utilised in the preparation of thalliumdiethyl nitrite and lactate, the former showing a similar stability to the corresponding nitrate. Since the author was unable to obtain thalliumdiisopropyl iodide, it was thought possible that the larger the aliphatic group attached to the thallium the less stable the compound might become. To test this the thalliumdiethyl salts were prepared from the formate up to the $n$-octoate, and the series shows a fall of melting point with rise of molecular weight and an increase of solubility. The formate, however, was not obtained pure for analysis, but the specimen gave a melting point $240-241^{\circ}$. The salts were prepared by the action of thalliumdialkyl hydroxides on the respective acids (see Cahours and Demarçay, Compt. rend., 1879, 88, 1112). The thalliumdiethyl acetate, m. p. $232-233^{\circ}$, appears to be purer than that obtained by Hartwig (Ber., 1874, 7, 298), which melted at $212^{\circ}$.

Three salts in the aromatic series, namely, thalliumdiethyl $p$-nitrobenzoate, $p$-iodobenzoate, and $m$-bromobenzoate have also been obtained. Magnesium isobutyl and isoamyl iodides react with thallic chloride in a similar manner to magnesium isopropyl iodide, causing quantitative reduction to thallous iodide.

Concentrated hydrochloric acid, thionyl chloride, ammonia gas, and mercuric chloride do not react with thalliumdiethyl chloride, but iodine trichloride even in the cold violently attacks the corresponding bromide, with the production of thallous iodide. This appears to be due to the action of chlorine in the presence of iodine, since solid iodine added to a boiling aqueous solution of thalliumdiethyl bromide has practically no action.

Meyer and Bertheim (Ber., 1904, 37, 2051), by the action of magnesium phenyl bromide on thallic chloride, obtained a compound stated to be thalliumdiphenyl bromide, which could not be prepared pure for analysis. It was also stated that on heating with fuming nitric acid for several hours in a sealed tube at $300^{\circ}$, the substance was not completely decomposed. The author has now obtained thalliumdiphenyl chloride, which does not melt at $288^{\circ}$, in a pure 
state, and finds that it is decomposed by fuming nitric acid even in the cold, and claims therefore that this is the first organo-derivative of thallium in the aromatic series to be produced. The product was obtained by the interaction of triphenylbismuthine and thallic chloride in cold anhydrous ether. Considerable difficulty was experienced in purifying the compound, this probably being due to a secondary reaction which produced small quantities of thalliumphenyl dichloride and inorganic derivatives of thallium, the reaction being represented as taking place in two stages :

1. $2\left(\mathrm{C}_{6} \mathrm{H}_{5}\right)_{3} \mathrm{Bi}+\mathrm{TlCl}_{3}=2\left(\mathrm{C}_{6} \mathrm{H}_{5}\right)_{2} \mathrm{BiCl}+\left(\mathrm{C}_{6} \mathrm{H}_{5}\right)_{2} \mathrm{TlCl}$.

2. $\left(\mathrm{C}_{6} \mathrm{H}_{5}\right)_{2} \mathrm{TlCl}+\mathrm{TlCl}_{3}=2 \mathrm{C}_{6} \mathrm{H}_{5} \cdot \mathrm{TlCl}_{2}$.

The reaction represented by the second equation is at present under investigation.

The compound thus formed is identical in properties with that produced from mercury diphenyl and thallic chloride in ethereal solution. Triphenylstibine and thallic chloride, however, react quantitatively and immediately in the cold in accordance with the equation :

$$
\left(\mathrm{C}_{6} \mathrm{H}_{5}\right)_{3} \mathrm{Sb}+\mathrm{TlCl}_{3}=\left(\mathrm{C}_{6} \mathrm{H}_{5}\right)_{3} \mathrm{SbCl}_{2}+\mathrm{TlCl} \text {. }
$$

In the case of triphenylarsine, a precipitate of yellow scales will be obtained after some time; the reaction is still under investigation.

EX P E R I M N T A L.

Thalliumdiethyl Nitrite.-Two grams of thalliumdiethyl iodide and 0.9 gram of silver nitrite were shaken in 70 c.c. of acetone, and the mixture was kept over-night. The precipitated silver iodide was filtered off and extracted with acetone, these washings being added to the main filtrate; this, on evaporation, yielded 1.0 gram of large, transparent plates, which did not melt at $290^{\circ}$ (Found :. $\mathrm{N}=4 \cdot 54 ; \mathrm{Tl}=66 \cdot 14 . \quad \mathrm{C}_{4} \mathrm{H}_{10} \mathrm{O}_{2} \mathrm{NTl}$ requires $\mathrm{N}=4 \cdot 54$; $\mathrm{Tl}=66.17$ per cent.). The nitrite is completely soluble in hot pyridine and insoluble in other organic solvents.

Thalliumdiethyl Lactate. - This was prepared in the way described above, 1.5 grams of silver lactate being employed. The product (1.5 grams), after four crystallisations from alcohol, gave small plates which suddenly decomposed without melting at $267.5^{\circ}$ (Found : $\mathrm{Tl}=58 \cdot 13 . \quad \mathrm{C}_{7} \mathrm{H}_{15} \mathrm{O}_{3} \mathrm{Tl}$ requires $\mathrm{Tl}=58 \cdot 04$ per cent.). The lactate is soluble in cold water, acetone, or alcohol, and easily soluble in boiling chloroform, toluene, or ethyl acetate.

Thalliumdimethyl Acetate.-By acidifying the hydroxide derived from 2.0 grams of thalliumdimethyl iodide with acetic acid and concentrating the solution, 1.2 grams of long, elongated plates were deposited, m. p. $293^{\circ}$ (Found: $\mathrm{Tl}=70 \cdot 17 \quad \mathrm{C}_{4} \mathrm{H}_{9} \mathrm{O}_{2} \mathrm{Tl}$ requires 
$\mathrm{Tl}=69.56$ per cent.). The salt is very soluble in water, alcohol, or acetone, less soluble in ether or petroleum.

Thalliumdiethyl Acetate.-By the interaction of the hydroxide from 3.42 grams of thalliumdiethyl bromide and 0.70 gram of acetic acid, 0.8 gram of short, white needles was obtained. After two crystallisations from water, these melted at 232-233 ${ }^{\circ}$ (Found: $\mathrm{Tl}=63 \cdot 25 . \quad \mathrm{C}_{6} \mathrm{H}_{13} \mathrm{O}_{2} \mathrm{Tl}$ requires $\mathrm{Tl}=63 \cdot 47$ per cent.). The solubility of this salt is the same as the above.

Thalliumdiethyl Propionate.-Using in this case 0.5 gram of propionic acid, 0.9 gram of fine, short needles was obtained on concentration, rn. p. 228-229 (Found : $\mathrm{C}=24 \cdot 70 ; \mathrm{H}=4 \cdot 65 ; \mathrm{Tl}=$ $60 \cdot 09,60 \cdot 54 . \quad \mathrm{C}_{7} \mathrm{H}_{15} \mathrm{O}_{2} \mathrm{Tl}$ requires $\mathrm{C}=25 \cdot 14 ; \mathrm{H}=4.51 ; \mathrm{Tl}=$ 60.66 per cent.). The salt is completely soluble in hot alcohol, ethyl acetate, toluene, or acetone, in cold pyridine or chloroform, moderately soluble in hot ether or carbon tetrachloride, and slightly soluble in light petroleum.

Thalliumdiethyl Valerate.-By the interaction of the hydroxide from 3.42 grams of thalliumdiethyl bromide and 1.07 grams of valeric acid, 1.9 grams of small needles were obtained, m. p. $215^{\circ}$ (Found : $\mathrm{C}=29 \cdot 20 ; \quad \mathrm{H}=5 \cdot 21 ; \mathrm{Tl}=56 \cdot 00,56 \cdot 04 . \quad \mathrm{C}_{9} \mathrm{H}_{19} \mathrm{O}_{2} \mathrm{Tl}$ requires $\mathrm{C}=29 \cdot 85 ; \mathrm{H}=5 \cdot 27 ; \mathrm{Tl}=56 \cdot 11$ per cent.). The salt is completely soluble in cold alcohol, ether, pyridine, chloroform or hot carbon tetrachloride, moderately soluble in cold toluene, acetone, or ethyl acetate, and insoluble in light petroleum.

Thalliumdiethyl Hexoate.-Prepared, in the way described above, from 2 grams of the bromide and 0.73 gram of the acid, 1.2 grams of product were obtained, which on crystallisation from acetone and light petroleum gave transparent needles half an inch in length, softening at $182^{\circ}$ and melting at $190^{\circ}$ (Found: $\mathrm{Tl}=54 \cdot 04$. $\mathrm{C}_{10} \mathrm{H}_{21} \mathrm{O}_{2} \mathrm{Tl}$ requires $\mathrm{Tl}=54.02$ per cent.). With the exception of its solubility in light petroleum, it agrees in all respects with the valerate.

Thalliumdiethyl $\mathrm{n}$-Octoate.-By means of 0.89 gram of $n$-hexoic acid, a hard solid mass ( $1 \cdot 3$ grams $)$ insoluble in water was obtained. This was crystallised twice from light petroleum, when long, transparent needles, m. p. $159^{\circ}$, were deposited (Found : $\mathrm{Tl}=50 \cdot 23$, $50 \cdot 03$. $\quad \mathrm{C}_{12} \mathrm{H}_{25} \mathrm{O}_{2} \mathrm{Tl}$ requires $\mathrm{Tl}=50 \cdot 27$ per cent.). The salt resembles the hexoate in its solubility.

Thalliumdiethyl $\mathrm{p}$-Nitrobenzoate.-To the hydroxide from 2 grams of thalliumdiethyl bromide was added 0.98 gram of $p$-nitrobenzoic acid, and the mixture was boiled and concentrated. The resulting solid, 1.2 grams, was crystallised twice from chloroform, when microscopic needles were obtained, m. p. $213^{\circ}$ (Found: $\mathrm{N}=3.59$; $\mathrm{Tl}=47 \cdot 19 . \quad \mathrm{C}_{11} \mathrm{H}_{14} \mathrm{O}_{4} \mathrm{NTl}$ requires $\mathrm{N}=3 \cdot 27 ; \quad \mathrm{Tl}=47 \cdot 59$ per cent.). The salt is completely soluble in cold pyridine, moderately 
GODDARD : ORGANO-DERIVATIVES OF THALLIUM. PART III. 39

soluble in alcohol or chloroform, slightly soluble in carbon tetrachloride, toluene, ethyl acetate, or acetone, and insoluble in ether or light petroleum.

Thalliumdiethyl p-Iodobenzoate- - 1.45 Grams of $p$-iodobenzoic acid being employed, 2.0 grams of small, white needles containing iodine were deposited. These decomposed with slight explosion at $220^{\circ}$ (Found: $\mathrm{Tl}=39 \cdot 70 . \quad \mathrm{C}_{11} \mathrm{H}_{14} \mathrm{O}_{2} \mathrm{ITl}$ requires $\mathrm{Tl}=40.03$ per cent.). The solubility is similar to that of the above nitrocompound.

Thalliumdiethyl $\mathrm{m}$-Bromobenzoate.-This was prepared in the usual manner, from 1.18 grams of $m$-bromobenzoic acid. The small, white needles ( 1.6 grams) obtained after two crystallisations from water melted with considerable gas evolution at $220^{\circ}$ (Found : $\mathrm{Tl}=43 \cdot 49 . \quad \mathrm{C}_{11} \mathrm{H}_{14} \mathrm{O}_{2} \mathrm{Br} T \mathrm{Tl}$ requires $\mathrm{Tl}=44 \cdot 10$ per cent.). The above compound is insoluble in acetone, but otherwise resembles the nitrobenzoate.

\section{Action of Iodine Trichloride on Thalliumdiethyl Bromide.}

To a suspension of 1.45 grams of the bromide in 40 c.c. of light petroleum 1.7 grams of iodine trichloride were slowly added, and an immediate liberation of iodine was noticed. After remaining over-night, the whole was boiled and filtered. All free iodine having been washed from the residue, the latter was found to be thallous iodide (Found: $I=61.91$. Calc., $I=61.64$ per cent.). The same result was obtained when the reaction was carried out in the cold.

\section{Action of Magnesium isoAmyl Iodide and of Magnesium isoButyl Iodide on Thallic Chloride.}

A solution prepared from 28.0 grams of isoamyl iodide and $\mathbf{3 . 2}$ grams of magnesium in dry ether was slowly added to a solution of $7 \cdot 13$ grams of thallic chloride in the same solvent. After standing half an hour, the solution was decomposed, but no trace of organic matter was found in the residue and 6.95 grams of thallous iodide were isolated. As the original thallic chloride should have yielded $7 \cdot 61$ grams, quantitative reduction had occurred.

The same result was obtained when magnesium isobutyl iodide was used.

\section{Action of Triphenylbismuthine on Thallic Chloride.}

Sufficient dry ether was added to 5.0 grams of triphenylbismuthine to effect solution, followed by 3.54 grams of thallic chloride in the same solvent. A white precipitate was immediately thrown 
down, and after remaining for a short time the whole became solid. The precipitate was filtered off and repeatedly shaken with acetone until the extract gave no solid on evaporation. The residue thus obtained (3.75 grams) was organic and contained thallium, but was not pure for analysis. Purification was carried out by crystallising from pyridine, then boiling with glacial acetic acid, and further crystallising from pyridine, the product being thoroughly washed with boiling acetone (Found : $\mathrm{Tl}=51 \cdot 44,51 \cdot 51,51 \cdot 71 ; \mathrm{Cl}=9 \cdot 26$, 9.01. $\quad \mathrm{C}_{12} \mathrm{H}_{10} \mathrm{ClTl}$ requires $\mathrm{Tl}=5 \mathrm{l} \cdot 84 ; \mathrm{Cl}=9.01$ per cent.). Thalliumdiphenyl chloride crystallises from pyridine in colourless, microscopic needles which do not melt at $288^{\circ}$ and are slightly soluble in boiling acetic acid, alcohol, ethyl acetate, or chloroform, and insoluble in ether, acetone, or light petroleum.

The above acetone extracts on evaporation gave 4.0 grams of diphenylchlorobismuthine (m. p. $185-186^{\circ}$ ), but no unchanged bismuthine, and traces of inorganic thallium products.

\section{Preparation of Thalliumdiphenyl Chloride by means of Mercury Diphenyl.}

To a solution of 2.8 grams of mercury diphenyl in 50 c.c. of dry ether, $2 \cdot 5$ grams of thallic chloride in the same solvent were added, when a white precipitate was immediately thrown down. After remaining for several hours, this was filtered off and extracted with benzene in a Soxhlet apparatus. The benzene removed some mercury phenyl chloride, m. p. $250^{\circ}$, and the residue, after purification, was analysed (Found : $\mathrm{Tl}=51.5 \mathrm{l} ; \quad \mathrm{Cl}=9.09$. Calc., $\mathrm{Tl}=51.84 ; \mathrm{Cl}=-9.01$ per cent.).

\section{Action of Triphenylstibine on Thallic Chloride.}

To a solution of $5 \cdot 25$ grams of the stibine in 50 c.c. of toluene, 3.1 grams of thallic chloride in 4.8 c.c. of ether were added. An almost white precipitate was immediately thrown down, which was filtered off after twenty-four hours. The residue ( 3.2 grams) was found to be thallous chloride. The filtrate, on evaporation, yielded 3.6 grams of triphenylstibine dichloride (m. p. $143^{\circ}$ ), no unchanged stibine being obtained. The process is therefore merely one of chlorination by thallic chloride.

The author is indebted to the Research Fund of the Chemical Society for a grant which has partly defrayed the expenses of this investigation.

The UnIVERsity,

Edgbaston, Birmingham.

[Received, November 5 th, 1921.] 